\title{
Plastic Flow Verification in a Tool Cavity for Production of Test Sample for Wettability Solders Measurement
}

\author{
MARIA KAPUSTOVA ${ }^{1}$, ROMAN KOLENAK ${ }^{1}$, ROBERT SOBOTA ${ }^{1}$, JOZEF BILIK ${ }^{1}$, VLADIMÍR ŠIMNA ${ }^{1}$, \\ MARTIN RIDZON ${ }^{2}$, CRISTINA STEFANA MIRON BORZAN ${ }^{3 *}$ \\ ${ }^{1}$ Slovak University of Technology in Bratislava, Faculty of Materials Science and Technology, Bottova 25, 91724 \\ Trnava, Slovakia \\ ${ }^{2}$ ZP Research and Development Centre, Kolkaren 35, Podbrezova, Slovakia \\ ${ }^{3}$ Technical University of Cluj-Napoca, 103-105Muncii Blvd., Cluj-Napoca, Romania
}

The paper describes the structural design, simulation and proper manufacture of a tool for manufacturing of test samples in spherical form. This shape is essential for an innovative assessment of solder wettability, since the small sphere by its ideal shape represents the total nonwettability of substrate surface. In order to verify the design of the shaping tool, a simulation software, type Deform was used, which allowed the FEM analysis of plastic flow in the tool cavity. Just after successful computer simulation, a shaping tool was designed and then manufactured in laboratory conditions, thus the fabrication of test samples in spherical form was successfully tested.

Keywords: soldering, wettability, solder, sample in spherical form, forming tool, optimization of semi-finished product, FEM analysis

Soldering is one of the oldest methods of hot joining of materials. It is defined as a metallurgical process of joining the metallic and non-metallic materials by use of a molten solder. The basic properties of solders include the wettability, which is defined as a capability of molten solder to adhere to the surface of joined material at a certain temperature. During wetting, the surface atoms and molten solder are brought to a close distance and thus create the conditions for formation of adhesive and cohesive forces. The qualitative criterion of wetting consists in wetting angle $\alpha$, which is included by the tangent with the surface of base metal at the point of contact with the ambient atmosphere. The wetting occurs just in the case if the wetting angle varies within the range of $0^{\circ}<\alpha<90^{\circ}$.

- $\alpha=$ from $0^{\circ}$ to $15^{\circ}$ excellent solder wettability

- $\alpha=$ form $15^{\circ}$ to $75^{\circ}$ good wettability

- $\alpha=$ from $75^{\circ}$ to $90^{\circ}$ impaired wettability

At $\alpha>90^{\circ}$ the solder does not wet the material surface and the solder is unsuitable for any soldering process. For calculation of wetting angle the following equation is used:

$$
\sigma_{\mathrm{SV}}-\sigma_{\mathrm{SL}}=\sigma_{\mathrm{LV}} \cdot \cos \alpha
$$

then, from equation (1) the following is concluded:

where:

$$
\cos \alpha=\frac{\sigma_{\mathrm{SV}}-\sigma_{\mathrm{SL}}}{\sigma_{\mathrm{LV}}}=\frac{\sigma_{\mathrm{H}}}{\sigma_{\mathrm{LV}}}
$$

$\sigma_{\mathrm{SV}}$ - surface energy between the surface of base metal and the ambient atmosphere,

$\sigma_{\mathrm{LV}}$ - surface energy between the surface of base metal and the molten solder,

$\sigma_{\mathrm{SL}}-$ surface energy between the molten solder and the ambient atmosphere,

$\sigma_{\mathrm{H}}-$ adhesion stress, eventually energy.

A schematic diagram of wetting the solder with the contact angle of $\alpha=0^{\circ}$ to $90^{\circ}$, which wets the surface of base metal is shown in figure 1 and figure 2 shows the solder with the contact angle of $\alpha>90^{\circ}$, which does not wet the base metal [1-5].

\footnotetext{
*email: borzan_cristina@ymail.com
} 


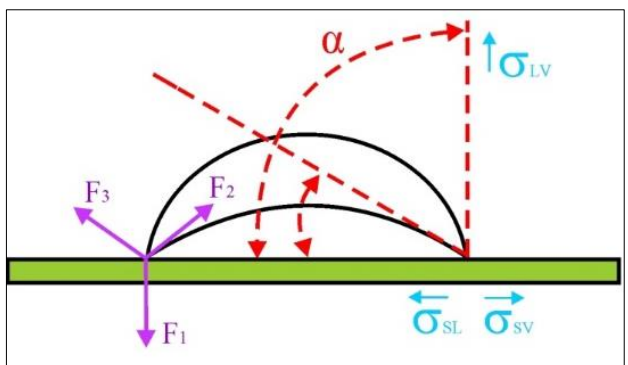

Fig. 1. Scheme of solder wetting for $\alpha=0^{\circ}$ to $90^{\circ}$ [6] $\alpha$ - wetting angle, $F_{1}$ - gravitation forces of atoms of surface layer in parent metal and molten solder, $\mathrm{F}_{2}$ - gravitation forces of atoms of ambient environment, $\mathrm{F}_{3}$ - gravitation forces of adjacent atoms in molten solder

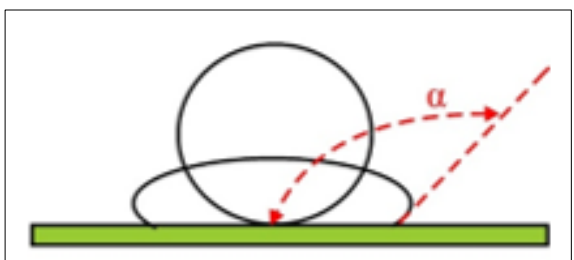

Fig. 2. Scheme of solder non-wetting for $\alpha>90^{\circ}$

The research activities and production practice at present employ several experimental methods for determination of solder wettability in molten condition. For research activities, the goniometric method of wettability measurement is mostly used.

The goniometric method is used mainly in electronic industry, electrical engineering and in machinery industry, as well - accordingly wherever soldering is applied. The shape of the test sample is very important in the evaluation of solder wettability, as the initial shape of the sample affects the final shape of a drop on the substrate surface. Theoretically it can be derived that the sphere-shaped solder sample is ideally shaped as the sphere represents a complete non-wettability of the substrate surface. The advantage of the above mentioned method is that the wettability tests can be also performed using a small amount of solder and testing at high temperatures is possible, while the sphere is the most advantageous solder form [1-6].

In order to achieve higher accuracy of the goniometric method of the solder wettability measurement, a new forming tool was designed to produce a test sample. The test sample will have the specific sphere shape which represents the complete non-wetting of the substrate surface.

\section{Experimental part}

The designed solder test sample for the goniometric method of wettability measurement will have the shape of the sphere with a diameter of $5 \mathrm{~mm}$. A special tool will be used for the sphere manufacture, while this tool consists of two mutually symmetrical parts that have hemispherical cavities. The sphere-shaped test sample with a $5 \mathrm{~mm}$ diameter will be prepared by connecting the individual parts. The tool is structurally designed to ensure that the upper part is guided to the lower part without the need for its firm fixing in the used device that produces the required forming force. The used device is a hydraulic table press CDC2 with a nominal force of $20 \mathrm{kN}$ and is determined for common pressing and assembly works.

The shape and accurate dimensions of the forming tool are protected by a patent: the utility model no. 7909 published in the Gazette of the Industrial Property Office of the Slovak Republic no. 04/2017. The tool model and drawing documentation of the tool used for the sphere manufacture are described in the figure 3.

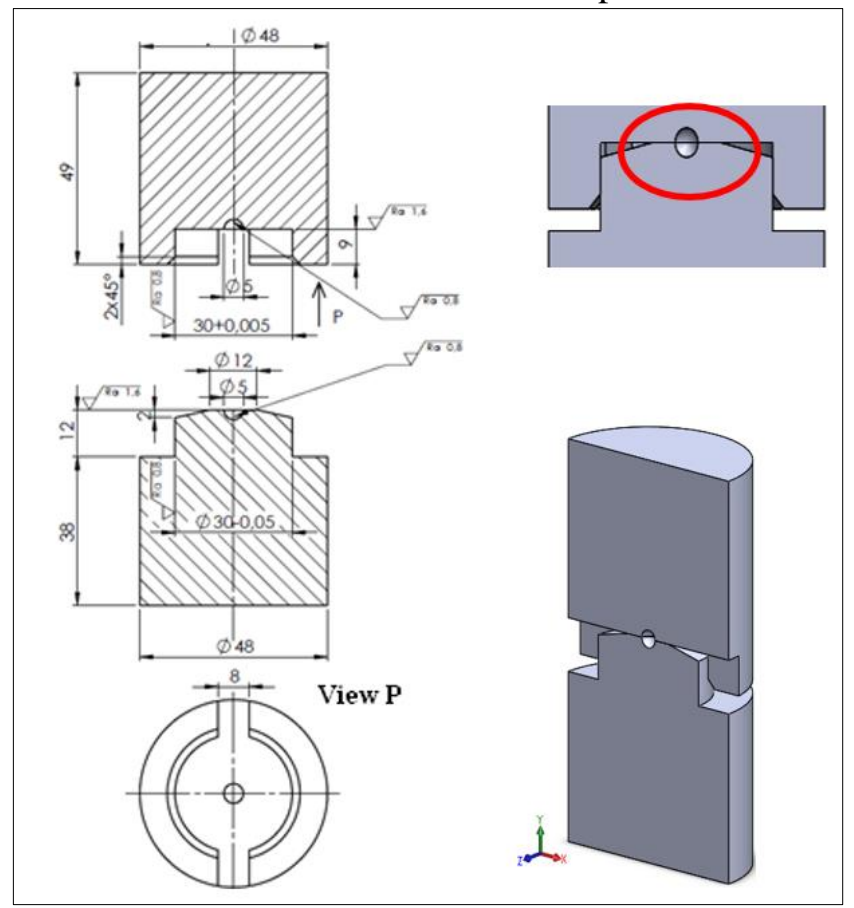

Fig. 3. The tool for production of test sample 


\section{FEM analysis of forming process}

Before production of the forming tool itself used for the sphere manufacture it was necessary to verify the correctness of its construction design by the simulation software. The FEM analysis of the forming process allows to observe the material plastic flow and determine the perfect filling of the tool cavity. When using Finite Element Method (FEM), the area deformed by forming is separated to finite amount of elements with particular shape and each element has its own approximation.

In order to perform areas tasks, a triangular element and approximation function of linear or cubic multi-nominal type are chosen. In the area of bulk forming for a calculation with the help of FEM analysis mostly volume elements (3Delements) are used. The principles of this method are described in detail in listed literature [7-10].

Balance equations are prepared for particular elements and a system of differential equations will be developed. After solving the below mentioned equations, results of strain, stress and temperature fields in a formed body and to follow the flow of solid-plastic or elastic-plastic bodies are achieved [11-13]. Numeric analysis of forming processes uses equations 3-7 for calculation of effective stresses $\sigma_{\mathrm{ef}}$ and effective strains $\varphi_{\mathrm{ef}}$

$$
\begin{aligned}
& \sigma_{e f}=\frac{1}{\sqrt{2}} \cdot \sqrt{\left|\sigma_{1}-\sigma_{2}\right|^{2}+\left|\sigma_{2}-\sigma_{3}\right|^{2}+\left|\sigma_{3}-\sigma_{1}\right|^{2}} \\
& \sigma_{\mathrm{ef}}=3 . \mathrm{I}_{2 \mathrm{D}}{ }^{1 / 2}
\end{aligned}
$$

Where: $\mathrm{I}_{2 \mathrm{D}}$ - the second (quadratic) stress deviator

$$
\begin{aligned}
& I_{2 D}=\frac{1}{6} \cdot\left[\left|\sigma_{1}-\sigma_{2}\right|^{2}+\left|\sigma_{2}-\sigma_{3}\right|^{2}+\left|\sigma_{3}-\sigma_{1}\right|^{2}\right] \\
& \varphi_{e f}=\frac{\sqrt{2}}{3} \cdot \sqrt{\left|\varphi_{1}-\varphi_{2}\right|^{2}+\left|\varphi_{2}-\varphi_{3}\right|^{2}+\left|\varphi_{3}-\varphi_{1}\right|^{2}}
\end{aligned}
$$

In order to mathematically express the plastic flow of material with hardening, a relation according to authors' Levy-Misses equation 7 is used.

$$
\frac{\varphi_{1}-\varphi_{2}}{\sigma_{1}-\sigma_{2}}=\frac{\varphi_{2}-\varphi_{3}}{\sigma_{2}-\sigma_{3}}=\frac{\varphi_{3}-\varphi_{1}}{\sigma_{3}-\sigma_{1}}=\frac{3}{2} \frac{\varphi_{e f}}{\sigma_{e f}}
$$

where:

$\varphi_{1} \varphi_{2} \varphi_{3}$ - principal strains, $\sigma_{1} \sigma_{2} \sigma_{3}$ - principal stresses

Numeric simulation of forming processes usually consists of the following three phases:

Pre-processing - preparation phase which includes preparation of models, i.e. inserting of geometric models in supported format from CAD system. All marginal input conditions and selection of elements, material and machine parameters, etc. are entered.

Processing - phase calculation using of FEM analysis.

Post-processing - output phase of simulation software which enables to depict achieved results of FEM simulation.

\section{Results and discussions}

\section{Verification of the tool design using FEM simulation}

Computer simulation of forming process was performed through the programme DEFORM-3D. It is a highperformance FEM simulation system designed for three-dimensional (3D) analysis of material flow within broad scope of forming processes. It is a practical and effective tool for prediction of the material plastic flow in forming tools for the purpose of reduction of production costs and acceleration of the whole production process. It is used for FEM simulation of drawing, die forging, rolling, extruding, etc. [14-17].

This programme is suitable for simulation of forming processes with regard to hot, warm and also cold forming. The numeric simulation reliability depends on the correct definition of the input conditions, e. g. object type, import geometry of the tool and semi-finished product, temperature, mesh (40 000 elements), material type (lead), boundary conditions, movement (hydraulic press), friction (shear coefficient of friction 0.12). The information database necessary for the initiation of the forming process simulation was generated. The simulation of the material plastic flow in the tool cavity shown in figure 4 confirmed the correct construction design of the forming tool cavity and the sphere-shaped formed piece showed no defects or surface flaws. 


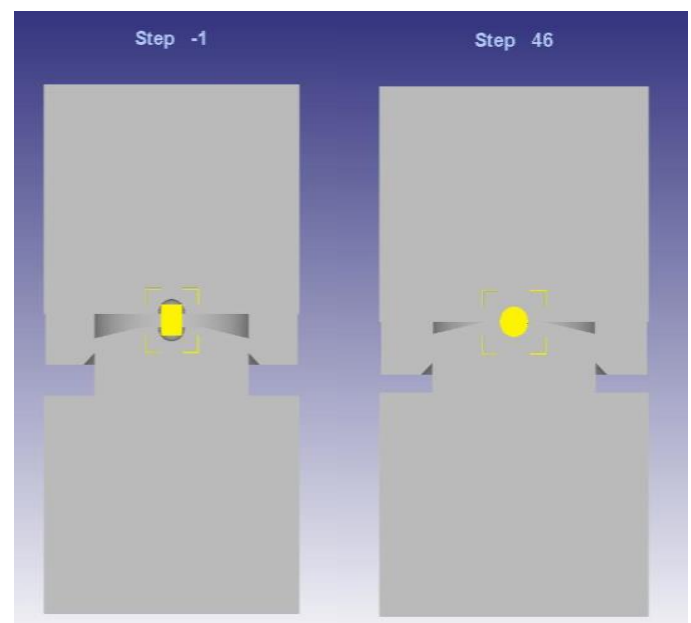

Fig. 4. The FEM simulation of the material flow in tool

The FEM simulation using Deform software was an essential instrument also for designing of the shape and dimensions of the input semi-finished product for the sphere manufacture. The volume of the formed material necessary for the perfect filling of the tool cavity was determined by the principle of volume constancy i.e. semifinished product volume $=$ sphere volume $=$ const $=65.416 \mathrm{~mm}^{3}$.

The semi-finished product used for the manufacture of a $\emptyset 5$ diameter sphere is a roller whose $\varnothing 4$ diameter resulted from the construction design of the tool cavity. The roller height has been optimized in the range of values 5.3 to 5.4 $\mathrm{mm}$ due to the use of FEM simulation. The performed optimization of the semi-finished product height dimensions using the FEM analysis presented in figure 5 shows that a semi-finished product with a height of $5.37 \mathrm{~mm}$ filled the tool cavity perfectly and one with a height of $5.4 \mathrm{~mm}$ already showed an excess of material.

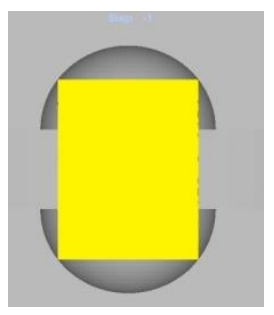

Dimensions of semiproduct $\varnothing 4 \times \mathrm{h}[\mathrm{mm}]$

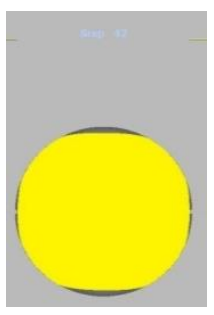

$\mathrm{h}=5.3 \mathrm{~mm}$

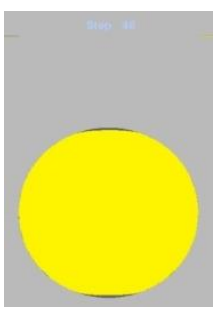

$\mathrm{h}=5.35 \mathrm{~mm}$

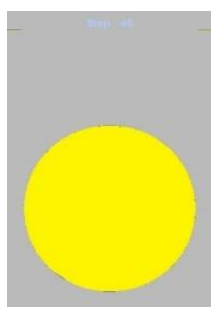

$\mathrm{h}=5.37 \mathrm{~mm}$

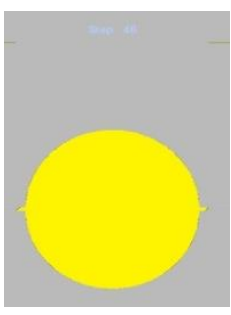

$\mathrm{h}=5.4 \mathrm{~mm}$

Fig. 5. The optimization of semi-finished product dimensions by using FEM

This excess material leaked into the gap between the two parts of the forming tool (fig. 6).

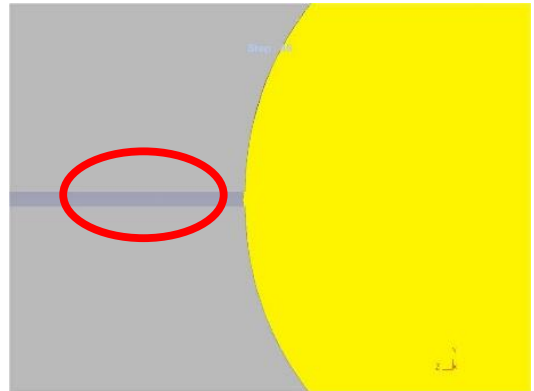

a)

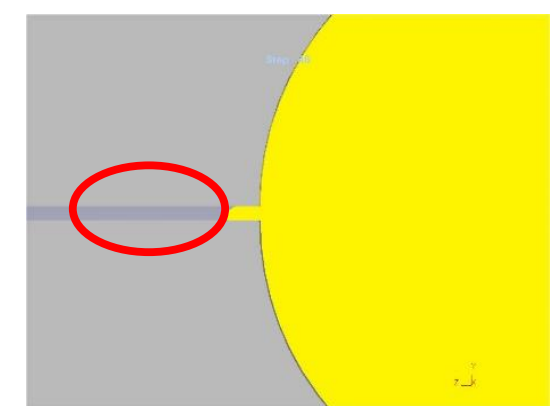

b)

Fig. 6. The detail of the tool cavity filling

a) semi-finished product $\varnothing 4 \times 5.37 \mathrm{~mm}$, b) semi-finished product $\emptyset 4 \times 5.4 \mathrm{~mm}$

The FEM analysis of the plastic flow in figure 7 shows the perfect filling of the tool cavity with a $\emptyset 4 \times 5.37 \mathrm{~mm}$ semi-finished product and the final sphere shape without any surface defects or folds, as well. The results of output phase, i.e. the simulation post processing, is the course of effective strain, effective stress and principal stress in final shape forging piece are shown in figures 7,8 . 


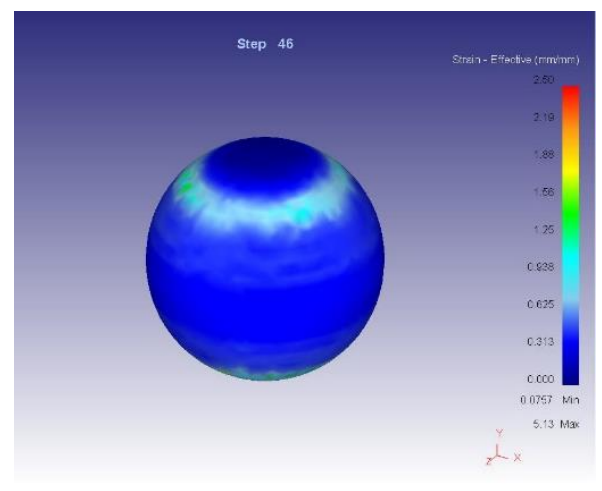

Fig. 7. The FEM analysis of sphere- shaped and the course of effective strain in the final shape of piece

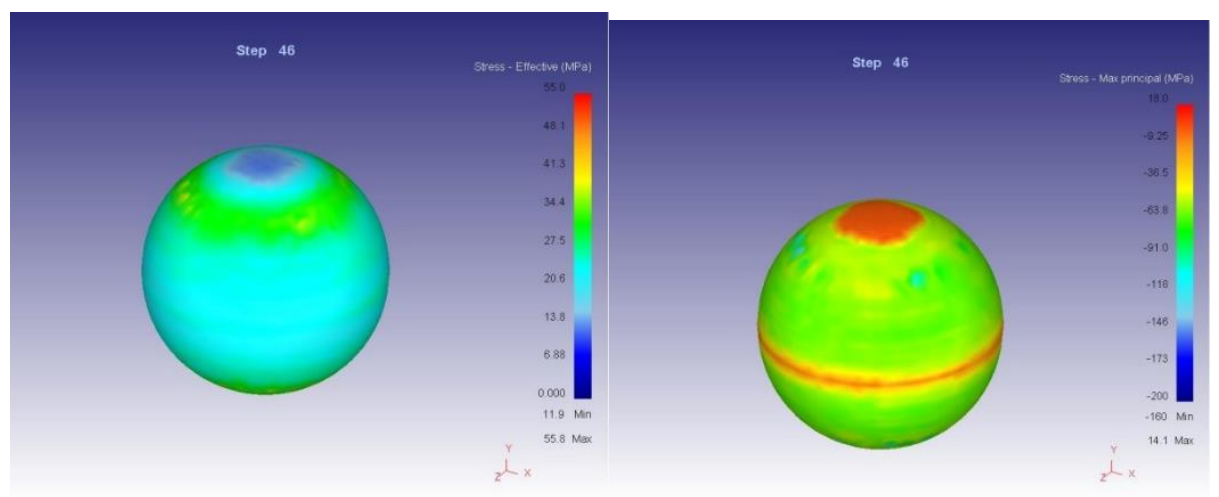

Fig. 8. The course of effective stress and principal stress in the final shape of piece

After the successful optimization of semi-finished product dimensions and the FEM simulation of the material plastic flow in the tool cavity the manufacture of the forming tool itself was performed. The individual tool parts were made of the chromium - manganic structural steel $16 \mathrm{MnCr} 5$ by using technology of machining. The control of various dimensional characteristics after the surface machining process is discussed in publications $[18,19]$. The measurement results are greatly influenced by the used measurement strategy [20]. Consequently, both tool parts were heat treated. In order to eliminate the risk of the tool cavity not being completely filled with the material, a semi-finished product with dimensions $\emptyset 4 \times 5.4 \mathrm{~mm}$ was finally recommended for the test sample production. For the semi-finished product fabrication a fixture was designed, whose shape and dimensions are illustrated in figure 9.
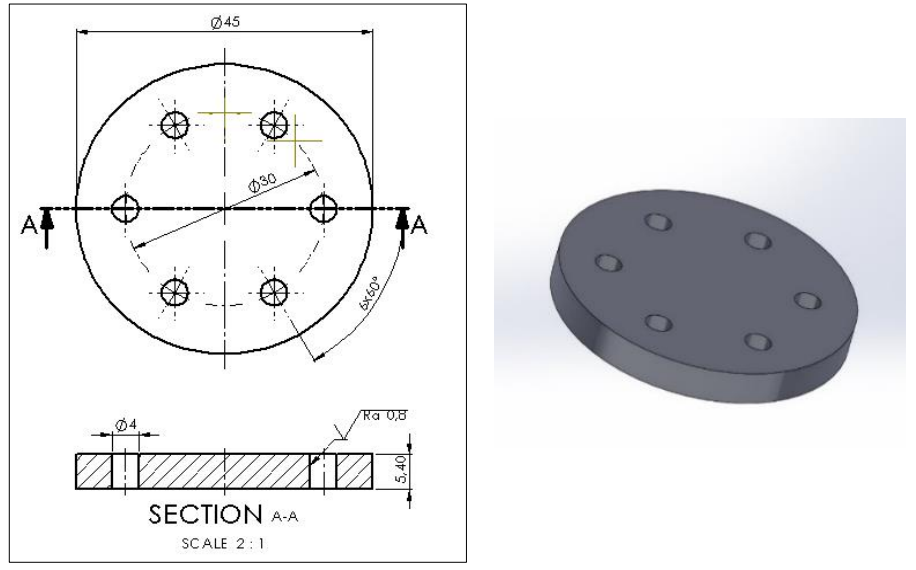

Fig. 9. The design of the fixture for semi-finished product preparation

The semi-products manufactured using the fixture will be roller-shaped castings. A melt made of alloys of nonferrous metals intended for solders will be poured into the holes of the required dimension $\emptyset 4$. The $\mathrm{Al}$ material type EN AW 6082 with a strength of $310 \mathrm{MPa}$ was used for the manufacture of the fixture. The aluminium alloys marked AW 6082 contain alloying elements silicium, magnesium and manganese. The higher content of these elements enhances the strength and hardness of the alloy ad improves its machinability. The forming tool after the testing of the sphere production is shown in figure 10. 


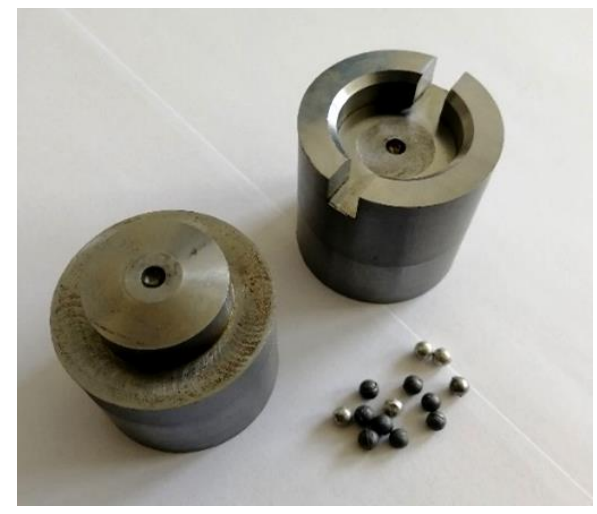

Fig. 10. The forming tool after the testing of the sphere production

\section{Conclusions}

The simulation software plays an important role in design and manufacture of forming tools as this software provides a virtual display of the examined forming process under definition of the input parameters similar to reality. The FEM analysis reliably verifies the correctness of the construction design of forming tools and in our case confirmed the design accuracy of the forming tool used for the sphere-shaped test sample preparation. This shape is essential for an innovative assessment of solder wettability, since the small sphere by its ideal shape represents the total non-wettability of substrate surface.

The advantage of the goniometric method of measuring wettability is that it can be used in many cases where other methods cannot be used, mainly due to its simplicity. A wide variety of basic materials can be used in this method. Wettability tests can also be carried out using a small amount of solder and high temperature testing is also possible.

The goniometric method of measurement is used mainly in electronic industry, electrical engineering and in machinery industry, as well - accordingly wherever soldering is applied. The advantage of the designed and manufactured forming tool is its versatility, as it will be suitable for production of test samples for solders made of all soft and mouldable metals, for example based on $\mathrm{Sn}, \mathrm{In}, \mathrm{Zn}, \mathrm{Pb}$ etc.

Acknowledgment: This work was supported by the Slovak Research and Development Agency under the contract no. APVV-17-0025 and no. APVV-0023-12. The paper was also prepared with the support of the VEGA 1/0089/17 project: Research of new alloys for direct soldering of metallic and ceramic materials.

\section{References}

1. KOLEŇÁK, R., et al, Solder Surf. Mt. Tech., 23(4), 2011, p. 224.

2. YU, W., LIU, Y., LIU, X., Mater. Design, 150, 2018, p.9.

3. KOLEŇÁK, R, et al., INT. J. MECH. SCI. 10(2), 2016, p. 95.

4. LIN, Q., YE, CH., SUI, R., CI, Microelectron Reliab., 98, 2019, p. 112.

5. KOLEŇÁK, R., RUŽA, V., Soldering of materials, STU, Bratislava, 2007, p. 151.

6. KOLEŇÁK, R., TURŇA, M., Soldering of lead-free solders, STU, Bratislava, 2006, p. 150.

7. DIXIT, P.M., DIXIT U.S., Modelling of Metal Forming and Machining Processes by Finite Element and Soft Computing Methods, Springer Verlag, London, 2008.

8. CHAMPION, E. R., Finite Element Analysis in Manufacturing Engineering, McGraw-Hill, Inc. New York, 1993.

9. KOBAYASHI S., OH, S.I., ALTAN, T., Metal forming and the Finite-Element Method, Oxford University Press, London, 1989.

10. KAPUSTOVÁ, M., BÍLIK, J., Technical Gazette, 24(5), 2017, p. 1323.

11. HOSFORD, W.F., CADDELL, R.M., Metal Forming: Mechanics and Metallurgy, Cambridge University Press, New York, 2011.

12. ALTAN, T., OH, S.I., GEGEL, H., Metal Forming-Fundamentals and Application, ASM, Metals Park, OH, 1983.

13. RADFORD, J.D, RICHARDSON, D.B.: Production Engineering Technology, Third Edition, MacMillan Publishers LTD, London, 1980.

14. KAPUSTOVÁ, M., et al. Mat. Plast., 54, no. 2, 2017, p. 326.

15. KAPUSTOVÁ, M., SOBOTA, R., Mater. Sci. Forum, 952, 2019, p. 235.

16. LEE, R.S., JOU, J.L., J. Mater. Process. Technol., 140(1-3), 2003, p. 43.

17. KARNEZIS, P., FARRUGIA, D.C.J., J. Mater. Process. Technol., 80-81, 1998, p. 988.

18. MORAVČ́́KOVÁ, J., et al. J. Mater. Eng. Perform. 27(10), 2018, p. 5417.

19. KOŠŤÁL, P., et al., Novel Trends in Production Devices and Systems IV, 1. vyd. Zurich: Trans Tech Publications, 2018 , p. 92.

20. MORAVČ́́KOVÁ, J., POKORNÝ, P., Acta Polytech. Hung., 15(6), 2018, p. 7.

Manuscript received: 5.09.2019 